\title{
Pemberdayaan Masyarakat melalui Pelatihan Security Awarness bagi Pegawai Unit Penyelenggara Bandar Udara Ranai-Natuna
}

\author{
I Gusti Agung Ayu Mas Oka \\ Jurusan Manajemen Bandar Udara, Politeknik Penerbangan Palembang \\ e-mail: ig ayumasoka@poltekbangplg.ac.id \\ M. Erawan Destyana \\ Jurusan Manajemen Bandar Udara, Politeknik Penerbangan Palembang \\ e-mail: erawan@poltekbangplg.ac.id \\ Yulius Bhanu \\ Jurusan Manajemen Bandar Udara, Politeknik Penerbangan Palembang \\ e-mail: bhanu@poltekbangplg.ac.id
}

\begin{abstract}
Abstrak
Beberapa kasus pelanggaran terhadap Daerah Keamanan Terbatas masih sering terjadi, menunjukan bahwa perlunya upaya peningkatan keamanan daerah keamanan terbatas melalui penambahan sarana-prasana, maupun pelatihan bagi personil yang menangani keamanan penerbangan. Oleh karena itu, Politeknik Penerbangan Palembang bekerjasama dengan UPBU Ranai-Natuna melaksanakan pemberdayaan masyarakat melalui pelatihan security awareness bagi pegawai honorer UPBU Ranai-Natuna. Adapun tujuan dari pelatihan ini adalah para peserta mampu meningkatkan kesadaran akan pentingnya keamanan, mengenali segala bentuk ancaman dan mengantisipasi/menanggulangi ancaman di lingkungan bandar udara. Kegiatan dilaksanakan selama 3 (tiga) hari, dari tanggal 1 sampai dengan 3 Desember 2020, di UPBU Ranai-Natuna, yang diikuti oleh 20 orang pegawai honorer UPBU Ranai-Natuna. Hasil dari kegiatan ini, dapat disimpulkan pelatihan security awareness berjalan dengan baik dan berhasil mencapai tujuan pelatihan, yang dibuktikan dengan seluruh peserta dinyatakan lulus. Hasil evaluasi yang diperoleh dari kuisioner kepada para peserta mendapatkan penilaian baik pada unsur instruktur, dan cukup pada unsur pelayanan panitia penyelenggara dan kurikulum diklat. Hal ini menunjukan bahwa instruktur merupakan faktor penentu utama keberhasilan peserta dalam mengikuti pelatihan dan kulitas layanan panitia penyelenggara masih perlu ditingkatkan.
\end{abstract}

Kata kunci: Keamanan Penerbangan, Security Awarness

\begin{abstract}
Several cases of violations against the Limited Security Area are still frequent, showing that there is a need for efforts to increase the security of the limited security area through the addition of facilities, as well as training for personnel who handle aviation security. Therefore, the Palembang Aviation Polytechnic in collaboration with UPBU Ranai-Natuna carried out community empowerment through security awareness training for UPBU Ranai-Natuna honorary employees. The purpose of this training is that the participants are able to raise awareness of the importance of security, recognize all forms of threats and anticipate/overcome threats in the airport environment. The activity was held for 3 days, from 1 to 3 December 2020, at UPBU Ranai-Natuna, which was attended by 20 honorary UPBU Ranai-Natuna employees. The results of this activity, it can be concluded that the security awareness training went well and succeeded in achieving the training objectives, as evidenced by all the participants having passed. The results of the evaluation obtained from the questionnaire for the participants received good ratings on the instructor element, and sufficient on the service elements of the organizing committee and the training curriculum. This shows that the instructor is the main determining factor for the success of the participants in participating in the training and the quality of the organizing committee's service still needs to be improved.
\end{abstract}

Keywords: Aviation Security, Security Awarness 
I Gusti Agung Ayu Mas Oka, M. Erawan Destyana, Yulius Bhanu

Pemberdayaan Masyarakat melalui Pelatihan Security Awarness bagi Pegawai Unit Penyelenggara Bandar Udara Ranai-Natuna

\section{Pendahuluan}

Undang-Undang Nomor 1 Tahun 2009 tentang Penerbangan, pasal 1 menyatakan bahwa keamanan penerbangan adalah suatu keadaan yang memberikan perlindungan kepada penerbangan dari tindakan melawan hukum melalui keterpaduan pemanfaatan sumber daya manusia, fasilitas, dan prosedur. Pasal 327 menyatakan badan usaha bandar udara atau unit penyelenggara bandar udara wajib membuat, melaksanakan, mengevaluasi, dan mengembangkan program keamanan bandar udara di setiap bandar udara dengan berpedoman pada program keamanan penerbangan nasional. Selanjutnya untuk menjalankan amanah Undang-Undang tersebut, telah ditetapkan Keputusan Menteri Perhubungan Republik Indonesia Nomor KM 211 Tahun 2020 tentang Program Keamanan Penerbangan Nasional, di mana pada Bab III pasal 3.4 menyatakan Kepala Kantor Unit Penyelenggara Bandar Udara (UPBU) dan Pimpinan Badan Usaha Bandar Udara (BUBU) bertanggung jawab terhadap keamanan bandar udara yang dioperasikan. Di mana dalam melaksanakan tanggung jawab tersebut, Kepala Kantor UPBU dan Pimpinan BUBU bertugas merencanakan, menyediakan dan mengembangkan sumber daya dan fasilitas keamanan sesuai persyaratan keamanan penerbangan yang meliputi antara lain: perkantoran, sumber dara manusia, peralatan keamanan, anggaran keuangan, fasilitas pelatihan (training), kebutuhan administrasi dan pusat penanggulangan keadaaan darurat keamanan bandar udara (emergency operation centre) beserta fasilitas pendukungnya.

Beberapa penelitian tentang pentingnya keamanan penerbangan diantaranya menurut Zulaichah (2013) dalam penelitiannya menyatakan bahwa keamanan penerbangan merupakan bagian penting dalam operasi bandar udara. Bandara yang aman menunjukan bahwa bandara tersebut memiliki manajemen yang bagus. Selanjutnya Hariyanti (2019) menyatakan bahwa untuk dapat mewujudkan pengamanan yang optimal di perimeter bandar udara, maka perlu menerapkan aturan-aturan penerbangan yang telah ditetapkan sehingga mendukung operasional penerbangan yang aman, lancar, nyaman dan efisien. Begitu pula dalam penelitiannya Kustoro (2012) menyatakan bahwa pengawasan keamanan di suatu bandar udara terhadap penumpang, barang dan kendaraan sebaiknya dimulai sejak dari area publik yang setiap orang masih bebas keluar masuk tanpa harus menunjukkan kartu pengenal (pas bandar udara), hal ini diperlukan untuk lebih terciptanya situasi aman bagi setiap penumpang. Menurut Susanto (2018), perbaikan pagar dan penambahan personil pengamanan sangat berpengaruh terhadap keselamatan lalu lintas udara.

Dalam rangka melaksanakan Program Keamanan Penerbangan Nasional, telah ditetapkan Peraturan Menteri Perhubungan Nomor 33 Tahun 2015 tentang Pengendalian Jalan Masuk (Access 
Control) ke Daerah Keamanan Terbatas di Bandar Udara, di mana beberapa pasal dalam peraturan tersebut telah diubah menjadi Peraturan Menteri Perhubungan Nomor 167 Tahun 2015. Di mana pada pasal 2 mengklasifikasikan daerah keamanan bandar udara terdiri dari: Daerah Keamanan Terbatas (Security Restricted Area), Daerah Steril (Sterile Area), Daerah Terbatas (Restricted Area) dan Daerah Publik (Public Area). Pada pasal 3 menyatakan bahwa Daerah Keamanan Terbatas harus dilindungi dengan pembatas fisik dan selalu diawasi, diperiksa pada selang waktu tertentu, dan diberi tanda peringatan keamanan penerbangan.

Beberapa pelanggaran terhadap Daerah Keamanan Terbatas yang diperoleh dari media massa di mana adanya penumpang gelap yang bersembunyi di ruang roda pesawat. Pada tanggal 18 Februari 1981, Tarsono ikut menjadi penumpang gelap dengan rute penerbangan dari semarang ke Jakarta. Pada Tanggal 23 September 1997, Siswandi dan Manto menjadi penumpang gelap penerbangan dari Medan menuju Jakarta. Kasus ketiga terjadi pada tanggal 7 April 2015, Mario menjadi penumpang gelap pesawat GA 177 dengan rute Pekanbaru menuju Jakarta. Kasus pelanggaran lainnya terjadi tanggal 19 April 2010, di mana pesawat latih menabrak pengendara motor saat akan mendarat di Bandara Budiarto. Selain itu pada tanggal 7 Agustus 2013, pesawat Lion Air menabrak sapi di Bandara Gorontalo. Kasus-kasus pelanggaran terhadap daerah keamanan terbatas tersebut, menunjukan bahwa perlunya upaya peningkatan keamanan daerah keamanan terbatas melalui penambahan sarana-prasana, maupun pelatihan bagi personil yang menangani keamanan penerbangan.

Berdasarkan hal tersebut di atas, Politeknik Penerbangan Palembang bekerjasama dengan UPBU Ranai-Natuna menyelenggarakan kegiatan Pemberdayaan Masyarakat melalui pelatihan security awareness bagi pegawai honorer UPBU Ranai-Natuna. Adapun tujuan dari pelatihan ini adalah para peserta mampu meningkatkan kesadaran akan pentingnya keamanan, mengenali segala bentuk ancaman dan mengantisipasi/menanggulangi ancaman di lingkungan bandar udara.

\section{Metode}

Metode yang digunakan dalam kegiatan pengabdian kepada masyarakat ini dalam bentuk pelatihan dengan menyediakan jasa layanan bersertifikat kepada masyarakat, dengan tahapan pelaksanaan kegiatan sebagai berikut:

1. Persiapan, pada tahap ini dilakukan koordinasi dengan UPBU Ranai-Natuna tentang pelatihan yang dibutuhkan dan selanjutnya dituangkan dalam perjanjian kerjasama antara Politeknik Penerbangan Palembang dengan UPBU Ranai-Natuna tentang penyelengaraan 
pendidikan dan pelatihan pemberdayaan masyarakat security awareness, dengan nomor HK.201/55/19/Poltekbang.Plg-2020. Koordinasi juga dilakukan di internal Politeknik Penerbangan Palembang untuk memastikan kesiapan tim yang akan berangkat ke natuna, tenaga pengajar, materi pembelajaran dan lain sebagainya.

2. Pelaksanaan, pada tahap ini diawali dengan pembukaan pelatihan, pelaksanaan pembelajaraan dan diakhiri dengan penutupan. Kegiatan pelatihan security awareness ini, dilaksanakan selama 3 (tiga) hari, dari tanggal 1 sampai dengan 3 Desember 2020, di UPBU Ranai-Natuna, yang diikuti oleh 20 orang pegawai honorer UPBU Ranai-Natuna. Adapun materi pelatihan meliputi wawasan kebangsaan, keselamatan penerbangan, kesehatan dan keselamatan kerja, regulasi keamanan penerbangan, pengenalan bandar udara dan security awareness. Kegiatan pelatihan ini dilakukan dengan tatap muka langsung.

3. Evaluasi, pada tahap ini dilakukan dengan memberikan ujian komprehensif untuk menilai tingkat keberhasilan peserta selama mengikuti pelatihan. Selain itu evaluasi juga dilakukan dengan pemberian kuisioner kepada peserta pelatihan untuk menilai kepuasan peserta terhadap tingkat pelayanan yang diberikan serta memberikan masukan bagi Politeknik Penerbangan Palembang dalam rangka meningkatkan layanannya.

\section{Hasil dan Pembahasan}

Pada tanggal 1 Desember 2020 pada pukul 08.00 WIB kegiatan diawali dengan pembukaan pelatihan, yang dihadiri oleh Wakil Direktur III Politeknik Penerbangan Palembang dan Kepala UPBU Ranai-Natuna. Berikut dokumentasi kegiatan pembukaan pelatihan:

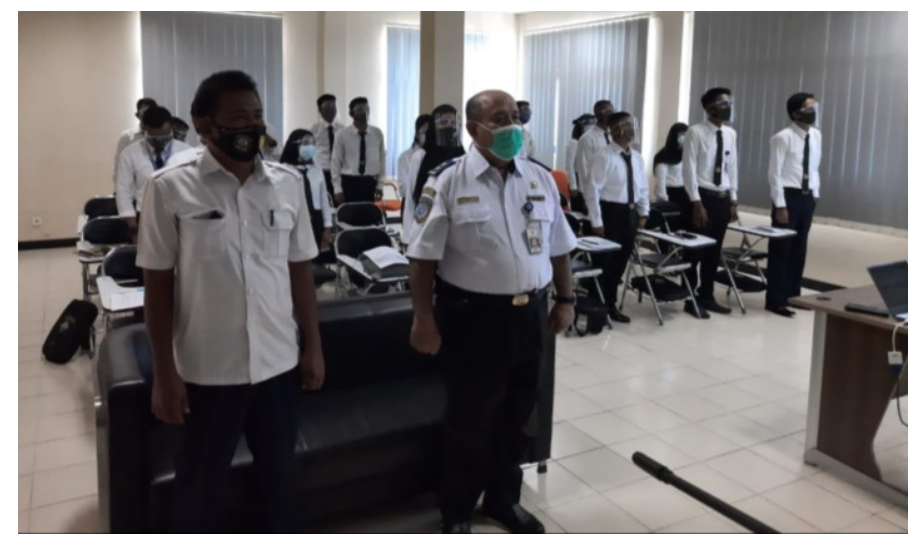

Gambar 1. Pembukaan Pelatihan Security Awareness

Metode pembelajaran yang digunakan untuk Pelatihan Security Awareness adalah dengan metode tatap muka yang bertempat di Ruang Rapat UPBU Ranai-Natuna. Demi tercapainya tujuan pembelajaran, kegiatan pembelajaran dilakukan setiap harinya dimulai dari pukul 08.00-16.00 WIB. 
Fasilitas kelas yang digunakan adalah fasilitas yang telah dipersiapkan oleh UPBU Ranai-Natuna, antara lain LCD Proyektor dan flipchart. Protokol Kesehatan tetap dijalankan dengan mewajibkan seluruh peserta untuk menggunakan masker saat pembelajaran berlangsung.

Setelah pembukaan pelatihan, kegiatan dilanjutkan dengan penyampaian materi pembelajaran yang meliputi wawasan kebangsaan dan keselamatan penerbangan. Pada tanggal 2 Desember 2020, kegiatan dilanjutkan dengan penyampaian materi kesehatan dan keselamatan kerja, regulasi keamanan penerbangan, dan pengenalan bandar udara. Pada tanggal 3 Desember 2020 dilanjutkan dengan penyampaian materi security awareness, serta ujian komprehensif. Peserta pelatihan sangat aktif mengikuti kegiatan, mulai dari bertanya, menjawab pertanyaan serta berdiskusi tentang materi pelatihan yang diberikan.

Evaluasi hasil pembelajaran dilakukan dengan prosentase $25 \%$ penilaian kedisiplinan peserta dan $75 \%$ hasil ujian komprehensif. Seluruh peserta dinyatakan lulus, yang menunjukan bahwa kegiatan pelatihan security awareness telah mencapai tujuan yang diharapkan yaitu meningkatkan kesadaran akan pentingnya keamanan, mengenali segala bentuk ancaman dan mengantisipasi/menanggulangi ancaman di lingkungan bandar udara. Hasil pembelajaran pelatihan security awareness ditunjukan sebagai berikut:

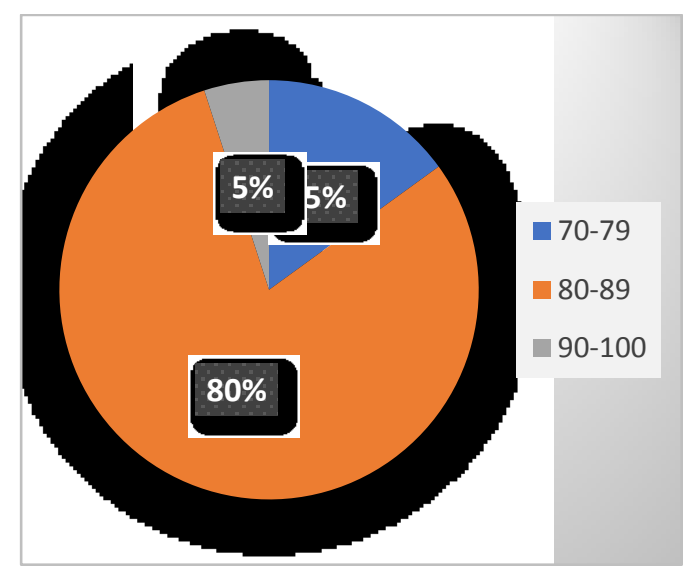

Gambar 2. Hasil Evaluasi Pembelajaran

Evaluasi pelaksanaan kegiatan pelatihan dilakukan dengan menyebar kuisioner kepada seluruh peserta. Adapun skala yang digunakan dalam evaluasi yaitu Tidak Baik dengan bobot nilai 1, Kurang Baik dengan bobot nilai 2, Cukup dengan bobot nilai 3, Baik dengan bobot nilai 4, Sangat Baik dengan bobot nilai 5, dan Memuaskan dengan bobot nilai 6. Adapun unsur yang dinilai meliputi: kurikulum diklat, pelayanan panitia penyelenggara, instruktur/pengajar. 
I Gusti Agung Ayu Mas Oka, M. Erawan Destyana, Yulius Bhanu

Pemberdayaan Masyarakat melalui Pelatihan Security Awarness bagi Pegawai Unit Penyelenggara Bandar Udara Ranai-Natuna

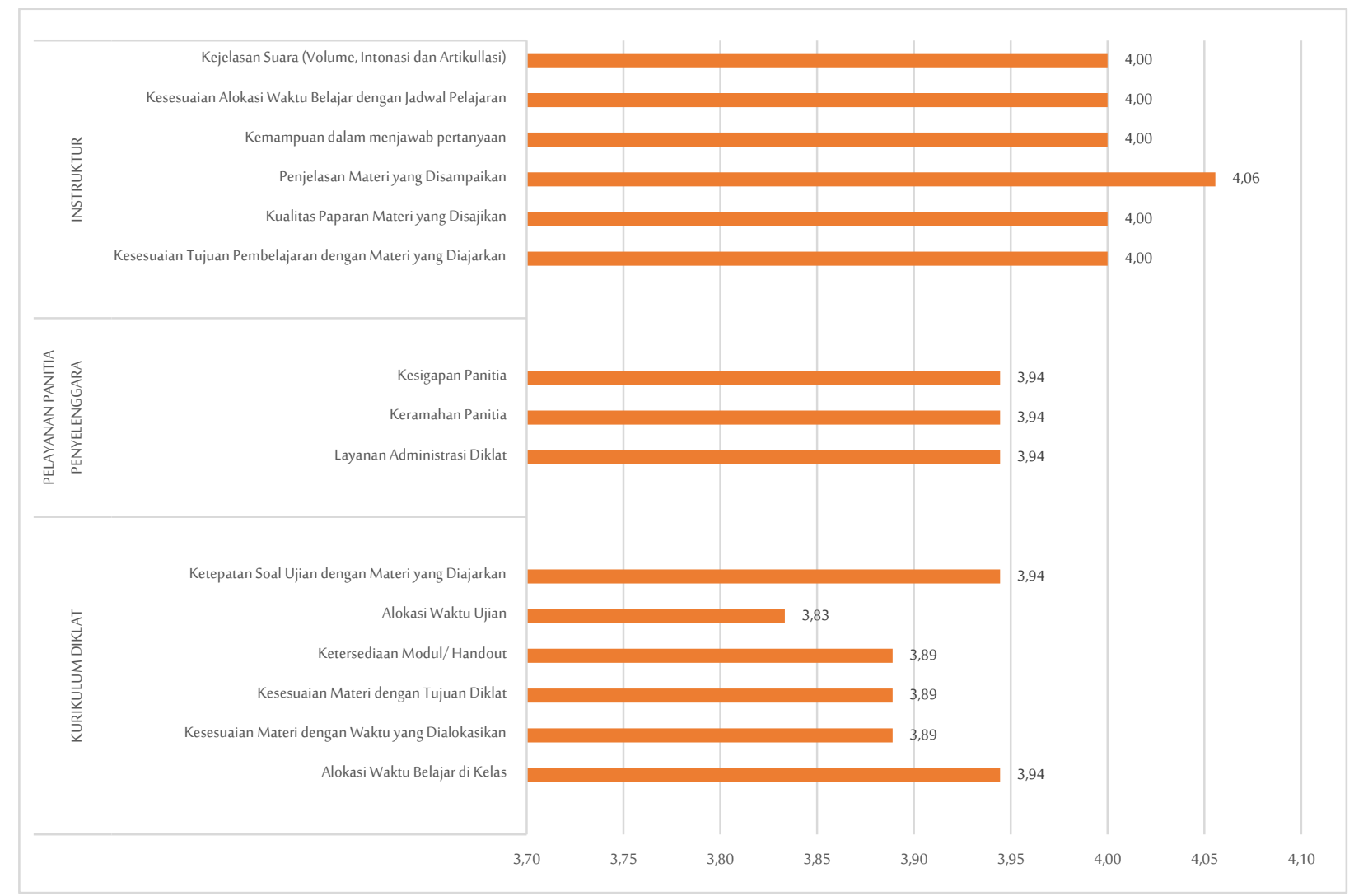

Gambar 3. Hasil Evaluasi Kegiatan

Berdasarkan hasil evaluasi, pada unsur instruktur mendapatkan penilaian baik dengan penilaian tertinggi ada pada penjelasan materi yang disampaikan. Pada unsur pelayanan panitia penyelenggara dan kurikulum diklat mendapatkan penilaian cukup, dengan penilaian terendah ada pada alokasi waktu ujian. Hal ini agar menjadi perhatian panitia penyelenggara untuk meningkatkan kualitas layanannya di kegiatan selanjutnya. Penilaian yang baik pada sisi instruktur dan lulusnya seluruh peserta pelatihan menunjukan bahwa instruktur merupakan faktor utama yang menentukan keberhasilan peserta pelatihan. Hal ini sesuai dengan penelitian yang telah dilakukan sebelumnya diantaranya Hartiwi (2020) dalam penelitiannya menyimpulkan bahwa pengajar yang tersertifikasi memiliki pengaruh yang signifikan terhadap kinerjanya. Selanjutnya Hatip (2018) dan Tahrir (2018) dalam penelitiannya menyimpulkan bahwa kompetensi dosen berpengaruh signifikan terhadap motivasi belajar mahasiswa.

Pendidikan dan pelatihan security awarness bagi petugas keamanan penerbangan sangatlah penting, hal ini didukung oleh beberapa penelitian sebelumnya diantaranya Sunarno (2019) dalam penelitianya menyimpulkan bahwa pengembangan SDM transportasi berbasis kompetensi dapat membantu badan pelaksana teknis organisasi untuk memiliki sumber daya manusia yang kompeten dan handal dalam bekerja. Selanjutnya Sutarwati (2018) dalam penelitiannya menyatakan personel 
I Gusti Agung Ayu Mas Oka, M. Erawan Destyana, Yulius Bhanu

Pemberdayaan Masyarakat melalui Pelatihan Security Awarness bagi Pegawai Unit Penyelenggara Bandar Udara Ranai-Natuna

keamanan penerbangan bandar udara harus memiliki kemampuan dan pengetahuan di bidang keamanan penerbangan yang dibuktikan dengan sertifikat kompetensi atau surat kecapakan personel. Begitu pula dalam penelitiannya Apriani (2020) menyatakan pengembangan SDM berbasis kompetensi merupakan kata kunci agar perusahaan yang sukses memiliki life cycle dalam hal mengembangkan pegawai menjadi talenta sukses.

\section{Kesimpulan}

Kegiatan pemberdayaan masyarakat melalui pelatihan security awareness bagi pegawai UPBU Ranai-Natuna berjalan dengan baik dan berhasil mencapai tujuan pelatihan, yang dibuktikan dengan seluruh peserta dinyatakan lulus. Berdasarkan hasil evaluasi terhadap kuisioner yang diisi oleh seluruh peserta, unsur instruktur mendapatkan penilaian baik, sedangkan unsur pelayanan panitia penyelenggara dan kurikulum diklat mendapatkan penilaian cukup, dan penilaian terendah ada pada alokasi waktu ujian. Hasil evaluasi ini menunjukan bahwa panitia penyelengara perlu meningkatkan kualitas layanannya. Penilaian yang baik pada sisi instruktur dan lulusnya seluruh peserta pelatihan menunjukan bahwa instruktur merupakan faktor utama yang menentukan keberhasilan peserta pelatihan.

\section{Ucapan Terima Kasih}

Terima kasih Penulis ucapkan kepada seluruh civitas academica Politeknik Penerbangan Palembang yang telah berperan serta dalam penyelenggaraan Diklat Pemberdayaan Masyarakat Security Awarness, sehingga kegiatan ini berjalan dengan lancar.Terima kasih pula, penulis ucapkan kepada UPBU, Direktur BUBU Ranai-Natuna, yang telah bekerjasama agar kegiatan ini dapat terlaksana. Semoga kerjasama ini dapat terus terjalin, dalam rangka mewujudkan keamanan penerbangan. Karya tulis ini dibuat khusus untuk mengenang Almarmuh Bapak Dadang Kusyadi, Wakil Direktur III Bidang Ketarunaan Politeknik Penerbangan Palembang yang meninggal setelah menjalankan tugas dalam kegiatan Pelatihan Security Awarness ini.

\section{Daftar Pustaka}

Apriani, N., Fatonah, F., \& Oka, IGA., A. (2020). Rancangan Sistem Pengolahan Sertifikat Berbasis Website sebagai Upaya untuk Peningkatan Evaluasi Kompetensi Safety Personel di Lingkungan PT. Angkasa Pura II (Persero). Jurnal Ilmiah Aviasi Langit Biru, 13(1), 17-28.

Hariyanti, A. N., Utami, S., \& Susanto, H. (2019). Kajian Pengamanan Perimeter Dalam Menunjang Keamanan Penerbangan di Bandar Udara Internasional Adi SoemarmoSurakarta. Jurnal Ilmiah Aviasi Langit Biru, 12(3), 147-154. 
I Gusti Agung Ayu Mas Oka, M. Erawan Destyana, Yulius Bhanu

Pemberdayaan Masyarakat melalui Pelatihan Security Awarness bagi Pegawai Unit Penyelenggara Bandar Udara Ranai-Natuna

Hartiwi, H., Kozlova, A., Y., \& Masitoh, F. (2020), The Effect of Certified Teacher and Principal Leadhership Toward Teachers' Performance. International Journal of Educational Review, 2(1), 70-88.

Hatip, M., Khoiriyah, Sanorsa, A., \& Qomariah, N. (2018). Kompetensi Dosen, Profesionalisme Dosen, dan Kecerdasan Spiritual Dampaknya Terhadap Motivasi Belajar Mahasiswa. JSMBI (Jurnal Sains Manajemen Dan Bisnis Indonesia), 8(1), 112-130.

Kustoro, L. (2012). Kinerja Peralatan Keamanan Bandara Adisutjipto Yogyakarta. Warta ArdhiaJurnal Penelitian Perhubungan Udara, 38(1), 56-73.

Sunarno, Solihin, \& Prasetyo, B. (2019). Membangun Strategi Pengembangan SDM Transportasi Udara. Jurnal Ilmiah Aviasi Langit Biru, 12(3), 43-52.

Susanto, A., \& Sutrisno, A. (2018). Analisa Standar Keamanan Terhadap Keselamatan Penerbangan di Bandar Udara Komodo Labuan Bajo. Jurnal Teknik \& Keselamatan Transportasi, 1(1), 14.

Sutarwati, S. (2018). Analisis Deskriptif Kompetensi Personel Keamanan Penerbangan di Bandar Udara Adi Soemarmo Boyolali. Jurnal Manajemen Dirgantara, 11(1), 43-50.

Tahrir (2018). Pengaruh Kompetensi Dosen Terhadap Motivasi Belajar Pada Mahasiswa Fakultas Psikologi UIN “SGD” Bandung. Psmpathic Jurnal Ilmiah Psikologi, 6(1), 756-765.

Zulaichah, \& Nahar, F. (2013). Sistem Pengelolaan Keamanan Penerbangan Untuk Mendukung Rencana Peningkatan Status Bandar Udara Menjadi Bandar Udara Internasional (Studi Kasus di Bandar Udara Abdulrachman Saleh-Malang). Warta Ardhia-Jurnal Penelitian Perhubungan Udara, 39(3), 192-206. 